
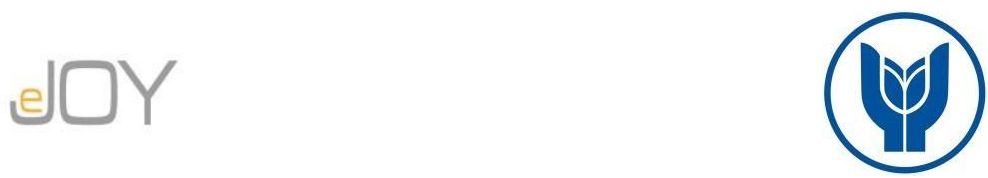

Karabıyık, C. / Journal of Yasar University, 2021, 16/63, 1133-1149

\title{
Ekonomik Kompleksite ve Doğrudan Yabancı Sermaye Yatırımları İlişkisi: BRICS-T Ülkeleri Üzerine Bir Panel Veri Analizi
}

\author{
The Relationship Between Economic Complexity and Foreign Direct \\ Investment: A Panel Data Analysis on BRICS-T Countries
}

\author{
Can KARABIYIK, Manisa Celal Bayar Üniversitesi, Türkiye, c_karabiyik@ hotmail.com \\ Orcid No: 0000-0002-7255-7946
}

\begin{abstract}
Öz: Bu çalışmada BRICS-T ülkelerinde ekonomik kompleksite ile doğrudan yabancı sermaye yatırımları arasındaki ilişkinin incelenmesi amaçlanmaktadır. Bu amaçla panel veri analizi yöntemi tercih edilmiştir ve 19952017 dönemini kapsayan bir veri seti kullanılmıştır. Çalışmada modellenen serilerde yatay kesit bă̆ımlılı̆̆ ve değişen varyans olduğu saptanmıştır. Bu nedenle serilerin durağanlı̆̆ yatay kesitsel genişletilmiş Dickey-Fuller birim kök testi ile, değişkenler arasındaki ilişkinin yönü Dumitrescu ve Hurlin nedensellik testi ile, değişkenler arasındaki ilişkinin büyüklüğ̈̈ ise uygulanabilir genelleştirilmiş en küçük kareler tahmincisi ile test edilmiştir. Analiz bulguları ekonomik kompleksiteden doğrudan yabancı sermaye yatırımları yönünde tek yönlü nedensellik ilişkisi olduğunu göstermektedir. Ayrıca ekonomik kompleksitenin doğrudan yabancı sermaye yatırımları üzerinde anlamlı pozitif etki meydana getirdiğine dair ampirik kanıt elde edilmiştir.
\end{abstract}

Anahtar Kelimeler: Ekonomik Kompleksite, Ekonomik Gelişmişlik, Doğrudan Yabancı Sermaye Yatırımları, Panel Veri Analizi

JEL Siniflandırmasl: F16, C23, O40, P45

\begin{abstract}
This study aims to examine the relationship between economic complexity and foreign direct investment in BRICS-T countries. For this purpose, panel data analysis method is preferred and a data set covering the period 1995-2017 is employed. It is found that the modelled series in this study have cross-sectional dependency and heteroscedasticity. For this reason, the stationarity of the series is tested by using cross-sectional augmented Dickey-Fuller unit root test, the direction of the relationship between the variables is tested by using Dumitrescu and Hurlin causality test and the size of the relationship between the variables is tested by employing feasible generalized least squares estimator. The analysis findings show that there is a one-way causal relationship towards from economic complexity to foreign direct investment. In addition, empirical evidence has been obtained that economic complexity has a significant positive effect on foreign direct investment.
\end{abstract}

Keywords: Economic Complexity, Economic Development, Foreign Direct Investment, Panel Data Analysis

\section{Giriş}

JEL Classification: F16, C23, O40, P45

Ekonomistler uluslararası gelir farklılığının sebeplerini uzun zamandır araştırmaktadırlar ve bunun arkasında çeşitli faktörler olduğunu iddia etmektedirler. Örneğin Acemoğlu (2010) kurumsal altyapının, Romer (1990) teknolojik gelişimin, Barro ve Gordon (1983) ise beşeri sermayenin ülkelerin zenginlikleri için belirleyici olduğunu öne sürmektedir. Öte yandan bir ulusun zenginliğinin tek bir faktöre bağlanamayacak kadar karmaşık olduğunu iddia eden çalışmalar da mevcuttur. Bu çalışmalardan birisi de Simoes ve Hidalgo (2011) tarafından yapılmıştır. Çalışmaya göre ulusların zenginliğini belirleyen faktörler çok boyutludur.

Klasik iktisat teorileri doğrusal ve statik modellere dayanmaktadır ve kompleks yapıya sahip modellerin çözümlenmesinde yeterli olamamaktadır (Eren 2013). İktisadi sistem ise karmaşık yapısıyla dikkat çekmektedir. 21. yüzyılın başından bu yana ekonomik yapı, 
neoklasik yaklaşımın bazı sınırlamalarının üstesinden gelmek için kompleksite bilimi çerçevesinde ele alınmaktadır. Çünkü Neoklasik yaklaşımın iktisadın ortak dilini temsil etmemeye başladığ iddia edilmektedir (Fontana 2010). Ancak buradaki bilimsel kullanımıyla "kompleks" ifadesi, anlam itibariyle günlük dildeki kaosu çağnıştıran "karmaşık" ifadesinden oldukça farklıdır. Bir sistem çok sayıdaki faktörün etkileşimi sonucunda birtakım özellikler gösteriyorsa kompleks olarak nitelendirilmektedir (Durlauf 1998, 157). Moleküllerin etkileşimiyle yaşamın meydana gelmesi, insanların etkileşimiyle ekonominin oluşması kompleks sistemlere örnek olarak gösterilebilmektedir. Kompleksite, çeşitli mikroekonomik yapı taşlarının belirli makroekonomik değişkenler üzerinde nasıl etki yarattığını göstererek iktisadi gerçekler hakkındaki anlayışımızı derinleştirme özelliğine sahiptir (Durlauf 1998, 158). Örneğin, balonlar ve çöküşler hisse senedi piyasalarının yaygın özellikleridir ve piyasa aktörlerinin etkileşimi sonucunda oluşmaktadır. Bu bağlamda yapılan değerlendirmeler ve modeller de yeniden şekillenmektedir.

Günümüzde ülkelerin ne ürettiği veya ne kadar ürettiği büyük önem taşımamaktadır. Bu bağlamda artık dış ticaret ile ekonomik performans ilişkisi araştırılırken yapılan ihracatın boyutu değil üretilen ürünlerin sofistikasyonu ve yaratılan katma değerin düzeyi dikkate alınmaktadır (Şahin ve Durmuş 2020, 335). Buna ilave olarak yakın zamanlara kadar doğal kaynakların ekonomik performans için büyük önem taşıdığı savunulmuştur. Ancak bu görüş bazı ampirik araştırmalar ile çelişmektedir. Örneğin Gylfason (2001) petrol, mineraller ve diğer doğal kaynaklar açısından zengin olan çoğu ülkedeki uzun dönem büyüme değerlerinin, faktör donatısı daha az olan ülkelere göre daha düşük olduğunu iddia etmektedir. Bu nedenle ülkelerin üretkenliklerinin, üretimin belirli yapı taşları olarak düşünülebilecek oldukça spesifik girdilerin veya becerilerin yerel mevcudiyetine bağlı olduğu öne sürülmektedir (Hidalgo 2009, 2).

Simoes ve Hidalgo (2011) ekonomik performansı belirleyen çok boyutlu faktörler için bir ölçek üzerine odaklanarak, ulusal ve bölgesel ekonomilerin gelişimini anlamamıza yardımcı olabilecek Ekonomik Kompleksite Gözlemevi'ni ${ }^{1}$ (EKG) kurmuşlardır. EKG ile ekonomilerin üretken yapılarının ve dış ticaret partnerlerinin gelişimi izlenebilmektedir. Bu ise, binlerce verinin bütüncül bir şekilde ele alınması aracılığıyla elde edilen büyük bir verinin daha iyi anlaşılmasına olanak sağlamaktadır. Ekonomik kompleksite (EK) kavramı, karmaşık sistemlerden, ağlardan ve bilgisayar biliminden faydalanarak ekonomik aktivitenin coğrafyasını ve dinamiklerini ele almaktadır. Ham doğal kaynaklar gibi basit ürünler ileri düzey bilgi ve yeteneklere çok az ihtiyaç duyarken; bilgisayarlar, robotlar veya uçaklar gibi karmaşık

\footnotetext{
${ }^{1}$ The Economic Complexity Observatory, bknz: https://legacy.oec.world/en/
} 
ürünler büyük miktarda bilgi gerektirmektedir. Bu açıdan bir ürünün karmaşıklığg, üretimi için gerekli bilgi ve beceri miktarına karşılık gelmektedir. Bir ülkenin EK düzeyi ise, kompleks ürünlerin çeşitliliği ve bu tür ürünlerin sadece bazı ülkelerde üretilebiliyor olmasıyla doğru orant1lidir (Antonietti ve Franco 2021, 225).

Bir ulusun zenginliği, bir ulusun sunabileceği ürün ve hizmetler dizisi olarak tanımlanan üretim yapısına sıkı sıkıya bağlıdır. Hidalgo ve Hausmann (2009) bu ürün ve hizmetler dizisinden yola çıkarak EK kavramını açıklamak için lego benzetmesini kullanmaktadırlar. Buna göre bir ekonomideki her bir üretim becerisi bir lego parçası olarak düşünülmektedir. Bu benzetmede bir ürün lego parçalarıyla oluşturulmuş bir modele ve bir ülke bir kutu legoya eşdeğerdir. Uluslar ancak gerekli tüm parçalarına sahip oldukları modelleri üretebileceklerdir. Kutudaki legolar ne kadar çeşitli ise, bir ulusun üretebileceği model o kadar komplike olmaktadır. Aynı mantıkla, ulusun mevcut yetenekleri ne kadar çeşitliyse üretebileceği ve rekabetçi bir şekilde ihraç edebileceği ürünler o kadar kompleks olmaktadır. Bir başka deyişle bir ülkenin EK'sı ihraç ettiği ürünlerin karmaşıklığına ve ihracat sepetindeki ağırlığına da bağlıdır (Sadeghi vd. 2020: 169)

Teknoloji de üretim sürecindeki bu becerilerden birisi niteliğindedir. Teknolojik ilerleme eğitim ve ar-ge harcamaları gibi iç politikalarla desteklenebileceği gibi teknoloji transferi vasıtasıyla dışsal kaynaklarla da beslenebilmektedir. Literatüre göre uluslararası teknoloji transferi üç yolla gerçekleşmektedir. Bunlar ticaret, doğrudan yabancı sermaye yatırımları (DYY) ve bilişim teknolojileri şeklindedir (Zhu ve Jeon 2007). Bu yollardan DYY girişleri ise genellikle teknoloji transferi ve daha rekabetçi ürün pazarlarına erişim gibi çeşitli faaliyetlerle ilişkilendirilmektedir (Mattoo, Olarreaga, ve Saggi 2004). DYY sanayileşmiş ekonomilerdeki yüksek teknolojinin gelişmekte olan piyasalara transfer edilmesini sağlayarak gelişmekte olan ülkelerin uluslararası rekabet gücünü arttırmaktadır. İç piyasaya gelen DYY, teknoloji transferiyle birlikte bilgi, beceri ve yeni pazarlama yöntemlerinin de ulusa kazandırılmasını mümkün kılmaktadır. Bu sayede üretime çeşitlilik kazandırılarak teknoloji yoğun ürünlerin ihracatı mümkün olmakta ve ihracata yönelik ürünlerin sofistike değeri artmaktadır (Torun ve Çabaş 2019). DYY ekonomik büyümeyi sadece doğrudan değil dolaylı olarak da etkileyebilmektedir. DYY beşeri sermaye ile etkileşime girerek gelişen piyasaların büyüme değerlerinde güçlü bir pozitif etki meydana getirirken, teknoloji açığını kapatabilmektedir (Li ve Liu 2005). Tüm bunlar ulusun üretim becerilerindeki artış üzerinden EK'yı etkileyebilmektedir. Bu açıdan literatürde DYY'nin EK üzerindeki etkisini araştıran çalışmalar yapılmıştır. Javorcik, Lo Turco, ve Maggioni (2018) ile Torun ve Çabaş (2019) bunlara örnek olarak gösterilebilir. 
Öte yandan EK'nın DYY üzerindeki etkisi de büyük önem taşımaktadır. Sadeghi vd. (2020) DYY'nin belirleyicilerini tarihsel olarak araştırmıştır. Yazarlara göre 1950'li yıllara kadar DYY doğal kaynak arayışında olmuştur. O dönemde zengin doğal kaynakları olan ülkeler, yüksek düzeyde DYY çekmiştir. 1960'l1 yıllarda ise, pazar büyüklüğünün önemi DYY'nin coğrafi dağılımının belirleyicisi olarak öne çıkmıştır. DYY'nin hizmetlere ve yüksek teknolojili üretim alanlarına yöneldiği 1980'li yıllardan beri doğal kaynaklar, ucuz işgücü ve ulusal pazar büyüklüğü gibi geleneksel belirleyicilerin önemi azalırken; üretim becerileri, teknoloji, kurumlara ve ticaret anlaşmalarına erişim kritik hale gelmiştir (Sadeghi vd. 2020, 168-69). Özetle günümüzde DYY kararı alınırken, yatırımın yapılacağı ülkenin sahip olduğu beceriler dikkate alınmaktadır. Bu beceriler ise ekonomik kompleksite kavramı ile ölçülmektedir. $\mathrm{Bu}$ ilişki Hidalgo ve Hausmann (2009)'ın lego benzetmesi ile açıklanacak olursa; yatırımcılar daha zengin lego kutularına yönelmişlerdir. Dolayısıyla teorik açıdan EK DYY üzerinde pozitif etki meydana getirebilmektedir. Çünkü Hartmann vd. (2017) tarafından da vurgulandığı üzere yüksek düzeyli EK sosyal sermaye, kurumsal kalite, profesyonel network oluşturma becerisi gibi yatırım için aranan niteliklerin göstergesidir.

Literatürdeki araştırmalar çoğunlukla DYY'nin büyüme, dış ticaret vb. makroekonomik büyüklükler üzerindeki etkisini incelemektedir. Ancak EK oldukça yeni olduğu için bu alandaki ampirik araştırmalar gerekli ilgiyi henüz görmemiştir. DYY'nin EK üzerindeki etkisi göz ardı edildiği gibi EK'nın DYY üzerindeki etkisi konusunda da literatürde boşluk mevcuttur. Bu araştırma, EK ile DYY arasındaki karşılıklı ilişkiyi analiz ederek literatürdeki boşluğu doldurmayı amaçlamaktadır.

Gelişmekte olan ülkelerin küresel ekonomideki payı 1990'lardan günümüze dikkate değer bir şekilde artmıştır. Özellikle BRICS ülkeleri olarak adlandırılan Brezilya, Rusya, Hindistan, Çin ve Güney Afrika bu artışta başı çeken ekonomiler arasındadır. Öte yandan Türkiye Ekonomisi de 21. Yüzyılın başından itibaren oldukça yüksek büyüme değerlerine ulaşmıştır. Yüksek ekonomik performansının bir sonucu olarak Türkiye, BRICS grubuyla birlikte anılmaya başlanmış ve bu grup BRICS-T ülkeleri olarak adlandırılmıştır. Literatürde BRICST ülkeleri üzerine yapılmış çok sayıda araştırma bulunmaktadır (bkz. Abubakirova vd., 2021; Karakurt, 2021; Yıldırım vd., 2019). Bu çalışma literatüre BRICS-T ülkelerinde EK ile DYY arasındaki ilişkiyi araştırarak katkıda bulunmaktadır. Çalışmada ilk olarak, EK'nın DYY üzerindeki etkisi panel veri metodolojisi uygulanarak incelenmiştir. İkinci olarak, DYY ve EK arasındaki nedensellik test edilerek BRICS-T ülkelerinde DYY ile EK arasındaki ilişkinin yönü saptanmıştır. Son olarak, nedensellik analizi sonuçları doğrultusunda oluşturulan model 
tahminlenerek EK ile DYY arasındaki ilişkinin kuvveti ölçülmüştür. Ampirik analiz sonuçları, EK'nın DYY için önemli ve pozitif etkili bir belirleyici olduğunu ortaya koymuştur.

\section{Literatür}

EK kavramı henüz çok yeni olmasına karşın, literatürde EK'nın makroiktisadi, sektörel, sosyoekonomik, çevresel vb. değişkenler için açıklayıcı güce sahip olduğunu öne süren çalışmalar gerçekleştirilmiştir. Örneğin EK'nın beşeri sermaye yapısı ve makroekonomik büyüme performansı üzerindeki etkisi Zhu ve Li (2017), bölgesel büyüme performans1 üzerindeki etkisi Chávez, Mosqueda, ve Gómez-Zaldívar (2017), gelir dağılımı eşitsizliği üzerindeki etkisi Hartmann vd. (2017), $\mathrm{CO}_{2}$ emisyonu üzerindeki etkisi Akiş ve Soyyiğit (2020), kişi başına düşen milli gelir üzerindeki etkisi Soyyiğit, Topuz, ve Özekicioğlu (2019) ve çevresel faktörler üzerindeki etkisi Swart ve Brinkmann (2020) tarafindan araştırılmıştır. Ayrıca EK yaklaşımıyla büyüme teorisinde sıklıkla tartışılan yakınsama hipotezi ülke ve bölgesel çapta Hausmann ve Hidalgo (2011) tarafından, EK'nin ihracat ürünleri üzerindeki çeşitlendirme etkisi ise Pinheiro vd. (2018) tarafından açıklamaktadır. EK'nın açıklama gücü ise zengin içeriği ve çok faktörlü yapısından kaynaklanmaktadır.

EK yaklaşımı ülkemizde de ilgi görmüş ve bu konuda ampirik çalışmalar gerçekleştirilmiştir. Güneri (2019) panel veri analiziyle 1981 - 2015 döneminde EK'nın büyüme için önemli bir belirleyici olduğunu bulmuştur. Yazara göre EK aynı zamanda yakınsama hızını arttırarak az gelişmiş ve gelişmekte olan ülkelerin refahına katkı sağlamakta ve çıktı volatilitesini azaltarak ekonomik istikrara katkıda bulunmaktadır. Yalta ve Yalta (2021) Orta Doğu ve Kuzey Afrika (MENA) ülkelerinde EK'nın belirleyicilerini 1970 ve 2015 yılları aralığında araştırmıştır. Analiz bulgularına dayanılarak beşerî sermaye ile EK arasında doğru, doğal kaynak rantı ile EK arasında ters yönlü ilişki olduğu saptanmıştır. Can ve Doğan (2018) ise bir ekonominin EK düzeyinin, o ülkenin finansal gelişmişlik düzeyi ile pozitif ilişkili olduğunu öne sürmektedir. Finansal gelişmenin özel sektöre verilen kredilerin milli gelire oranı ile ölçüldüğü çalışma Türkiye ekonomisi için gerçekleştirilmiştir ve Türkiye ekonomisinin 1970-2013 dönemini yansıtmaktadır. EK’nın küreselleşme ile ilişkili olduğunu iddia eden Ünzüle (2018) ise, 1975-2015 dönemi Türkiye ekonomisi verilerini kullanarak iktisadi, sosyal ve siyasi küreselleşme ile EK arasında istatistiksel olarak anlamlı ilişki saptamıştır. Analiz bulguları bu değişkenlerin uzun dönemde birlikte hareket ettiğini göstermektedir. Üç farklı tahminci ile gerçekleştirilen katsayı tahmini modellerine göre siyasi küreselleşme ile EK arasında negatif, iktisadi ve sosyal küreselleşme ile EK arasında pozitif yönlü ilişki mevcuttur. 
Daha önce de belirtildiği üzere EK'nın çok yeni bir kavram olmasına karşın çeşitli kapsamlardaki parametreler ile EK arasındaki ilişkiyi inceleyen çeşitli çalışmalar yapılmıştır. Ancak EK ile DYY arasındaki ilişkiyi araştıran çalışma sayısı yok denecek kadar azdır. Bu çalışmalardan ilki olarak sayılabilecek çalışma Wang ve Wei (2008) tarafından gerçekleştirilmiştir. Yazarlar Çin ekonomisinde ürün düzeyinde veriler kullanarak DYY'nin Çin ihracat ürünlerinin sofistikasyon derecesi üzerindeki etkisini incelemişlerdir ancak anlamlı bir sonuç elde edememişlerdir. Çalışma bulguları ihraç ürünlerinin sofistikasyon derecesinin beşerî sermaye ve kamu politikalarından güçlü bir şekilde etkilendiğini göstermektedir. Javorcik, Lo Turco ve Maggioni (2018) tarafından yapılan araştırmada ise, yükselen piyasa ekonomilerinde DYY girişlerinin ulusal üretim yapısı gelişimini hızlandırdığı iddia edilmektedir. 2006-2009 yılları arasında Türkiye'de faaliyet gösteren ve en az 21 çalışanı olan imalatçı firmalardan elde edilen veriler ile gerçekleştirilen çalışmanın sonuçlarına göre, yabancı sermayeli firmaların daha kompleks ürün üretme olasılığı daha yüksektir. Çalışmada gelişen ve yükselen piyasa ekonomilerindeki hükümetlerin, ulusal üretim yapılarını geliştirici politikalar geliştirme çabasında oldukları ve DYY'nin bu amaca ulaşmada yardımcı unsur olduğunun altı çizilmektedir. Torun ve Çabaş (2019) DYY ile EK arasındaki uzun dönemli ilişkiyle birlikte nedensellik ilişkisini de araştırmıştır. Türkiye'nin 1980-2016 yılları arasını yansıtan bir veri setiyle gerçekleştirilen ampirik analizin bulguları, DYY ile EK değişkenlerinin eşbütünleşik olduğunu göstermektedir. Ayrıca DYY'nin EK üzerinde pozitif etkisinin olduğuna dair kanıt elde etmişlerdir. Son olarak DYY'den EK yönünde tek yönlü nedenselliğin olduğuna dair kanıt elde etmişlerdir. DYY ile EK arasındaki ilişkiyi aydınlatmayı amaçlayan bir başka araştırma ise Sadeghi vd. (2020) tarafından yapılmıştır. Çalışma bir ülkenin DYY çekebilmesi için EK'nın yardımcı bir faktör olup olmadığı sorusunu sormaktadır. Türkiye dahil 79 ülkenin 19802014 dönemini ele alan çalışmanın bulgularına göre, EK düzeyi yüksek ülkeler üretken bilgiler üreterek ve bu doğrultuda yetenekler geliştirerek bir ekonominin cazibesini DYY için artırabilmektedir. Şahin ve Durmuş (2020) sanayileşme süreçleri devam eden Çin, Brezilya, Meksika, Arjantin, Hindistan, Tayland, Malezya, Filipinler, Türkiye ve Güney Afrika ekonomilerinde EK, finansal gelişmişlik, portföy yatırımları, DYY ve patent sayısı değişkenleri arasındaki ilişkiyi incelemiştir. 1990-2017 dönemini kapsayan bir veri seti ile gerçekleştirilen ampirik çalışmada, söz konusu değişkenlerin uzun dönemde birlikte etmediklerine dair kanıtlar elde edilmiştir. Öte yandan Çin ve Meksika ekonomilerinde DYY'den EK yönünde nedensellik olduğu sonucuna ulaşılmıştır. DYY ile EK arasındaki nedensellik ilişkisini araştıran bir diğer çalışma Khan, Khan, ve Khan (2020) tarafından yapılmıştır. 1985-2017 dönemi Çin ekonomisini ele alan araştırmanın bulguları, DYY ile EK arasında uzun dönemde çift yönlü 
nedensellik olduğunu göstermektedir. Kısa dönemli analiz bulguları ise EK'nın DYY'nin Granger sebebi olduğunu göstermektedir. Antonietti ve Franco (2021) da Şahin ve Durmuş (2020) ile tutarlı olarak, DYY'den EK yönünde nedensellik ilişkisi olduğuna dair bulgular elde etmişlerdir. Çalışma Türkiye dahil 117 ülkenin 1995-2016 dönemini kapsayan 22 yıllık bir veri setiyle gerçekleştirilmiştir. Gómez-Zaldívar, Llamosas-Rosas, ve Gómez-Zaldívar (2021) ise Meksika ekonomisi içerisinde DYY'nin bölgesel dağılımını 1999-2018 dönemi için incelemişlerdir ve EK düzeyi yüksek olan bölgelerin daha yüksek oranda DYY aldığı sonucuna ulaşmışlardır.

\section{Veri}

Bu çalışmada BRICS-T ülkelerinde DYY ile EK arasındaki ilişki 1995-2017 dönemi için araştırılmaktadır. Bu çalışma kapsamında kullanılan ekonomik kompleksite göstergesi Simoes ve Hidalgo (2011) tarafından geliştirilmiştir ve EK endeksi olarak adlandırılmaktadır. Simoes ve Hidalgo (2011) insan beyninin bilgiyle değer kazandığını ancak bir sabit disk ya da kaydedici gibi çalışmadığını ve büyük miktardaki ham bilgiyi depolamakta iyi olmadığını vurgulamaktadır. Ancak beynin karmaşık görsel kalıpları anlamlandırma konusunda mükemmel iş çıkardığını öne sürmektedirler. Bu basit fikirden yola çıkarak oldukça büyük bir veri setiyle çok boyutlu bir endeks geliştirmişler ve bunun insanlar tarafindan çok iyi kavranarak çeşitli araştırmaların gerçekleştirilebileceğini öne sürmüşlerdir. EK endeksi, bir ülkenin ihraç ürünlerinin çeşitliliği ve başka ülkelerde üretilip üretilmemesi hakkındaki bilgileri birleştirerek bir ülkenin üretken yapısının gelişmişliğini ölçmektedir (Hidalgo ve Hausmann 2009). Bu tanıma göre, kompleks ekonomiler daha yüksek çeşitliliğe ve aynı zamanda daha düşük yaygınlığa sahip ürünlere sahiptirler. Daha kompleks bir yapı için, bir ülkenin farklı türden ürünleri ihraç etmesi ve aynı zamanda yalnızca az sayıda ülke tarafından üretilen malları ihraç etmesi gerekmektedir (Yalta ve Yalta 2021, 7).

Çalışma kapsamında araştırılan BRICS-T ülkeleri uluslararası EK sıralamasında üst orta grupta yer almaktadır. 157 ülke arasından Çin 29., Türkiye 41., Hindistan 45., Brezilya 49., Rusya 44. ve Güney Afrika 59. Sırada yer almaktadır. Çalışmada kullanılan EK endeks verileri Ekonomik Kompleksite Gözlemevi'nden² alınmıştır. DYY hareketlerinin ölçümü için ise Dünya Bankası Dünya Bankası Dünya Gelişmişlik Göstergeleri veri tabanından elde edilmiş olan DYY girişlerinin milli gelire oranı serisi kullanılmıştır.

\footnotetext{
${ }^{2}$ https://oec.world/en
} 


\section{Yöntem ve Bulgular}

Literatürde EK-DYY ilişkisi için herhangi bir fikir birliği kurulamamıştır. İlişkinin niteliği ele alınan döneme ve incelenen ülkelere göre farklılık gösterebilmektedir. Bu çalışmada BRICS-T ülkelerinde EK ile DYY arasındaki nedensellik ilişkisinin yönünün ve büyüklügünün incelenmesi amaçlanmaktadır. Bu amaçla panel veri analizi yöntemi tercih edilmiştir.

Panel veri analizi uygulamasının ilk aşamasında, modelde kullanılan değişkenlerin homojenliği test edilmektedir. Çünkü uygulamada kullanılacak olan birim kök sınaması, eşbütünleşme testi ve nedensellik analizi, değişkenlerin homojen olup olmamasına göre farklılık göstermektedir. Bu amaçla Pesaran ve Yamagata (2008) delta testi kullanılarak değişkenlerin eğim parametrelerinin homojenliği sınanmıştır. Delta testi Denklem 1'de gösterilen eşitlik kullanılarak hesaplanmaktadır.

$$
\widehat{\Delta}=\sqrt{N}\left(\frac{N^{-1} \hat{S}-k}{\sqrt{2 k}}\right)
$$

Denklem 1'de yer alan $\hat{S}$ Swamy (1970) test istatistiğini, k açıklayıcı değişken sayısını, N ise ülke (yatay kesit) sayısını göstermektedir. $\widehat{\Delta}_{a d j}$ ifadesi ile gösterilen düzeltilmiş delta test istatistiği Denklem 2'de gösterilen eşitlik ile hesaplanmaktadır.

$$
\widehat{\Delta}_{a d j}=\sqrt{N}\left(\frac{N^{-1} \hat{S}-E\left(\widehat{\left.z_{l T}\right)}\right.}{\sqrt{\operatorname{Var}\left(\widehat{\left.z_{l T}\right)}\right.}}\right)
$$

Delta testi bulguları Tablo 1'de sunulmuştur.

Tablo 1. Delta Testi Bulguları

\begin{tabular}{|c|c|c|}
\hline & Test Istatistiği & Olasillk Değeri \\
\hline$\widehat{\boldsymbol{\Delta}}$ & 2.83 & 0.00 \\
\hline$\widehat{\boldsymbol{\Delta}}_{\boldsymbol{a d j}}$ & 3.04 & 0.00 \\
\hline
\end{tabular}

Delta testinin boş hipotezi, değişkenlerin eğim parametrelerinin homojen olduğu şeklindedir. Delta testi bulgularına göre boş hipotez \%1 anlamlılık düzeyinde reddedilmiştir. Modelde kullanılan değişkenlerin eğim parametreleri heterojendir. Bu bulgular, serilerin tahmin katsayılarının her bir yatay kesite göre değişken nitelikte olduğunu göstermektedir. $\mathrm{Bu}$ bulguya dayanılarak paneldeki tüm yatay kesitler için yapılacak eşbütünleşme çıkarımlarının güvenilir olduğu iddia edilebilir.

Panel veri analizi uygulamasının bir sonraki aşamasında, modelde kullanılan değişkenlerin yatay kesit bağımlılığı (YKB) test edilmektedir. Yatay kesitler arasındaki bağımlılığın varlığı bir başka deyişle yatay kesitlerin seriye gelen şoktan etkilenme dereceleri incelenmelidir. 
YKB'nin mevcut olması durumunda, YKB'yi dikkate alan tahmin yöntemlerinin kullanılması gerekmektedir. Ayrıca sahte regresyon sorununun önlenmesi amacıyla kullanılan birim kök sınamasının çeşidi YKB'nin varlığına göre belirlenmektedir. YKB olması durumunda YKB'yi dikkate almayan birim kök testlerinin kullanımı gerçekte durağan olan serilerin durağan olmadığına dair bulgular hatalı sunarak serinin farkının alınması suretiyle uzun dönemli iktisadi bilginin yok edilmesine sebep olabilmektedir. $\mathrm{Bu}$ nedenle YKB sinaması büyük önem taşımaktadır.

İlk değerlendirilecek olan YKB testi Breusch \& Pagan (1980) tarafindan geliştirilen Lagrange Multiplier (LM) testidir. LM testi Denklem 3 'te verilen eşitlik ile hesaplanmaktadır:

$$
L M=T \sum_{i=1}^{N-1} \sum_{j=i+1}^{N} \hat{\rho}_{i j}^{2}
$$

Denklem 3'te yer alan $\hat{\rho}$ ifadesi her bir denklemin regresyon tahminlemesinden edilen kalıntıların ikili korelasyon katsayılarıdır. Bu testteki boş hipotez YKB olmadığı şeklindedir.

Pesaran (2004) tarafından geliştirilen CD $_{\text {LM }}$ testi ise hem yatay kesit hem de zaman boyutunun büyük olduğu durumlar için uygulanabilmektedir. LM testinin geliştirilmiş hali olan CDLM testi Denklem 4'te gösterildiği gibi hesaplanmaktadır:

$$
C D_{L M}=\sqrt{\frac{1}{N(N-1)}} \sum_{i=1}^{N-1} \sum_{j=i+1}^{N}\left(T \hat{\rho}_{i j}^{2}-1\right)
$$

CD LM testindeki boş hipotez YKB olmadığı şeklindedir. Her iki teste ait bulgular Tablo 2'de raporlanmıştır.

Tablo 2. Yatay Kesit Testi Bulgular1

\begin{tabular}{|l|c|c|c|}
\hline \multicolumn{2}{|c|}{ Test İstatistiği } & Olasılık Değeri \\
\hline \multirow{2}{*}{ DYY } & LM & 44.09 & 0.00 \\
\cline { 2 - 4 } & CDLM & 5.31 & 0.00 \\
\hline \multirow{2}{*}{ EK } & LM & Test İstatistiği & Olasılık Değeri \\
\cline { 2 - 4 } & CDLM & 153.41 & 0.00 \\
\hline
\end{tabular}

Her iki teste ait bulgulara dayanılarak YKB’nin var olmadığı şeklindeki boş hipotez reddedilmektedir. Bu bulgular araştırmaya ikinci nesil tahmin yöntemleriyle devam edilmesi gerektiğini göstermektedir. Bu çalışmada Pesaran (2007) yatay kesitsel genişletilmiş Dickey Fuller testi (CADF) kullanılmıştır. CADF testi T>N durumu ile uyumludur (Pesaran 2007, 266). CADF testi Denklem 5'te ye alan regresyon modeli ile formülize edilmektedir (Pesaran 2007, 269).

$$
\Delta y_{i t}=a_{i}+b_{i} y_{i, t-1}+c_{i} \bar{y}_{t-1}+d_{i} \Delta \bar{y}_{t}+\varepsilon_{i t}
$$


CADF testi ADF regresyon modelini Denklem 5'te gösterildiği gibi, $\bar{y}_{t}$ ve $\Delta \bar{y}_{t}$ ifadelerini kullanarak genişletmiştir. Denklem 5 'te yer alan $\bar{y}_{t}$ ifadesi serilerin gecikmeli değerlerinin, $\Delta \bar{y}_{t}$ ifadesi ise farklarının ortalamasıdır. $\bar{y}_{t}$ ve $\Delta \bar{y}_{t}$ değerleri Denklem 6 ve 7 'de gösterildiği gibi hesaplanmaktadir:

$$
\begin{aligned}
\bar{y}_{t} & =\frac{1}{N} \sum_{i=1}^{N} y_{i t} \\
\Delta \bar{y}_{t} & =\frac{1}{N} \sum_{i=1}^{N} \Delta y_{i t}
\end{aligned}
$$

CADF testi ile her bir yatay kesit için ve panelin geneli için ayrı birer birim kök testi yapılması mümkündür. CADF testinin test istatistiği aşağıdaki gibi hesaplanmaktadır:

$$
\begin{gathered}
Y_{i t}=\left(1-\phi_{i}\right) \mu_{i}+\phi_{i} y_{i, t-1}+u_{i, t} \quad i=1,2, \ldots, N \quad t=1,2, \ldots, T \\
u_{i, t}=\gamma_{t} f_{t}+\varepsilon_{i, t}
\end{gathered}
$$

Denklem 9'daki $f_{t}$ ifadesi gözlenemeyen ortak faktörleri, $\varepsilon_{i, t}$ ifadesi ise yatay kesit hata terimini ifade etmektedir. CADF testinin boş hipotezi "seri birim kök içermektedir", alternatif hipotezi ise "seri durağandır" şeklindedir. Her bir yatay kesitin CADF test istatistiklerinin aritmetik ortalaması olan CIPS (Cross-Sectionally Augmented IPS) istatistiği panelin genelini ifade etmektedir ve aşağıdaki gibi elde edilmektedir:

$$
\text { CIPS }=\frac{\sum_{t=1}^{n} C A D F_{t}}{N}
$$

\begin{tabular}{|c|c|c|c|c|c|}
\hline \multirow{2}{*}{\multicolumn{2}{|c|}{ Değişkenler }} & \multicolumn{2}{|c|}{ Düzeyde } & \multicolumn{2}{|l|}{ 1. Fark } \\
\hline & & \multirow{2}{*}{$\begin{array}{l}\text { Sabitli } \\
-2.50\end{array}$} & \multirow{2}{*}{$\begin{array}{l}\text { Sabitli ve Trendli } \\
-2.44\end{array}$} & \multirow{2}{*}{$\begin{array}{l}\text { Sabitli } \\
-4.10^{* *}\end{array}$} & \multirow{2}{*}{$\begin{array}{l}\text { Sabitli ve Trendli } \\
-1.01\end{array}$} \\
\hline \multirow{6}{*}{ DYY } & Brezilya & & & & \\
\hline & Çin & -1.20 & -2.26 & $-4.65 * * *$ & $-3.83 *$ \\
\hline & Güney Afrika & -1.79 & -1.84 & -1.20 & $-5.27 * * *$ \\
\hline & Hindistan & $-3.46 * *$ & $-3.63 *$ & $-6.71 * * *$ & -3.29 \\
\hline & Rusya & -2.42 & -2.44 & -1.15 & -2.75 \\
\hline & Türkiye & -1.07 & -2.46 & -2.64 & -1.61 \\
\hline \multicolumn{2}{|c|}{ CIPS İstatistiği } & -2.07 & -2.51 & $-3.41 * * *$ & $-2.96 * *$ \\
\hline \multirow{4}{*}{ EK } & Brezilya & $-3.43 * *$ & 0.20 & -1.99 & $-5.01 * * *$ \\
\hline & Çin & -1.76 & -2.07 & $-3.73 * *$ & $-3.66^{*}$ \\
\hline & Güney Afrika & -2.21 & -2.83 & $-5.44 * * *$ & $-5.57 * * *$ \\
\hline & Hindistan & -2.49 & -2.73 & $-5.02 * * *$ & $-4.89 * *$ \\
\hline
\end{tabular}

DYY ve EK değişkenleri için hesaplanmış olan CADF ve CIPS istatistikleri Tablo 3'te sunulmaktadir:

Tablo 3. Birim Kök Analizi Sonuçları 


\begin{tabular}{|l|l|l|l|l|l|}
\hline \multirow{2}{*}{} & Rusya & -1.08 & 0.25 & -1.45 & 0.45 \\
\cline { 2 - 6 } & Türkiye & -1.61 & 0.25 & -1.77 & $-6.42 * * *$ \\
\hline CIPS İstatistiği & $\mathbf{- 2 . 1 0}$ & $\mathbf{- 1 . 1 5}$ & $\mathbf{- 3 . 2 3} * * *$ & $\mathbf{- 4 . 1 8 * * *}$ \\
\hline
\end{tabular}

Not: $*, * *$ ve *** sırasıyla $\% 10, \% 5$ ve \%1 düzeyinde anlamlılığı ifade etmektedir.

CADF testinin boş hipotezi serilerde birim kök olmadığı şeklindedir. Tablo 3'te yer alan bilgilere dayanılarak DYY serisi için düzeyde Hindistan hariç tüm ülkelerde hem sabitli hem de sabitli ve trendli modellerde boş hipotez reddedilememektedir. DYY serisinin birinci fark1 alındığında ise sabitli modelde Brezilya, Çin ve Hindistan serilerinin durağan olduğu görülmektedir. Güney Afrika, Rusya ve Türkiye serilerinin ise birim kök içerdiği saptanmıştır. Sabitli ve trendli modelde ise Çin ve Güney Afrika durağanken, Brezilya, Hindistan, Rusya ve Türkiye serilerinde birim kök olduğuna dair bulgular elde edilmiştir.

EK serisi için düzeyde yapılan CADF test istatistikleri sabitli modelde Brezilya'nın durağan olduğunu, diğer serilerin ise birim kök içerdiğini göstermektedir. Sabitli ve trendli model bulguları ise serilerin tamamında birim kök olduğunu göstermektedir. EK serisinin birinci fark serisi ile yapılan sabitli model CADF test sonuçlarına göre Çin, Güney Afrika ve Hindistan serileri durağan iken Brezilya, Rusya ve Türkiye serileri birim kök içermektedir. Ancak sabitli ve trendli model incelendiğinde Rusya hariç tüm serilerin durağan olduğu görülmektedir.

CADF panel birim kök testi sonuçlarının panel bazında değerlendirilme yapılmasına olanak sağlayan CIPS istatistikleri incelendiğinde, EK ve DYY değişkenlerinin hem sabitli hem de sabitli ve trendli modellerde düzeyde birim köke sahip oldukları görülmektedir. Serilerin farkı alındığında ise her iki değişken her iki modele göre \%1 anlamlılık düzeyinde durağan hale gelmektedir. Bu bulgular EK ve DYY değişkenlerinin I(1) (fark durağan) olduklarını göstermektedir.

Modelde yer alan serilerin birim kök sınamalarının ve eğim parametrelerinin homojenliğinin test edilmesinden sonraki aşamada uygulanacak olan eşbütünleşme testinin belirlenmesi gerekmektedir. Bu çalışmada kullanılan serilerde hem YKB hem de heterojenlik mevcuttur. Bu nedenle değişkenler arasındaki uzun dönemli ilişki Westerlund (2007) panel eşbütünleşme testi kullanılmıştır.

Westerlund (2007) eşbütünleşme testinde ilk olarak Denklem 11 ve 12'de gösterilen modeller tahmin edilerek panel test istatistikleri elde edilmektedir:

$$
\begin{gathered}
\Delta Y_{i t}=\delta_{i} d_{t}+\gamma_{i} x_{i t-1}+\sum_{j=1}^{p i} \alpha_{i j} \Delta Y_{i t-1}+\sum_{j=0}^{p i} \Delta x_{i t-1}+\varepsilon_{t} \\
Y_{i t-1}=\delta_{i} d_{t}+\gamma_{i} x_{i t-1}+\sum_{j=1}^{p i} \alpha_{i j} \Delta Y_{i t-1}+\sum_{j=0}^{p i} \Delta x_{i t-1}+\varepsilon_{t}
\end{gathered}
$$


Sonraki aşamada ise modelde uzun dönemli ilişkinin varlığını test etmek için Denklem 13 ve 14 ile ifade edilen grup ortalama istatistikleri elde edilmektedir:

$$
\begin{aligned}
G_{T} & =\frac{1}{N} \sum_{i=1}^{N} \frac{\alpha_{i}}{\operatorname{se}\left(\alpha_{i}\right)}, & G_{T} & \sim N(0,1) \\
G_{\alpha} & =\frac{1}{N} \sum_{i=1}^{N} \frac{T \alpha_{i}}{\alpha(1)}, & G_{\alpha} & \sim N(0,1)
\end{aligned}
$$

$G_{T}$ ve $G_{\alpha}$ grup ortalama istatistikleri için boş hipotez "bütün yatay kesitler için eşbütünleşme ilişkisi yoktur" şeklindedir. Westerlund (2007) yaklaşımında modellenecek olan serilerin I(1) oldukları varsayılmaktadır. Bu çalışma kapsamında kullanılan veri seti bu varsayım ile uyumludur. Westerlund (2007) eşbütünleşme testinde dört adet test istatistiği hesaplanmaktadır. $\mathrm{Bu}$ test istatistiklerinin ikisi grup ortalama istatistikleri olan $G_{T}$ ve $G_{\alpha}$, diğer ikisi ise panel istatistikleri olan $P_{T}$ ve $P_{\alpha}$ 'dır.

Tablo 4. Westerlund (2007) Eşbütünleşme Testi Sonuçları

\begin{tabular}{|c|l|c|c|}
\hline \multicolumn{2}{|c}{} & Test İstatistikleri & $\begin{array}{c}\text { Bootsrap Olasılık } \\
\text { Değeri }\end{array}$ \\
\hline $\boldsymbol{G}_{\boldsymbol{T}}$ & Grup Ortalamas1 & -2.48 & 0.03 \\
\hline $\boldsymbol{G}_{\boldsymbol{\alpha}}$ & Grup Ortalamas1 & -7.85 & 0.37 \\
\hline $\boldsymbol{P}_{\boldsymbol{T}}$ & Panel & -5.76 & 0.01 \\
\hline $\boldsymbol{P}_{\boldsymbol{\alpha}}$ & Panel & -8.33 & 0.01 \\
\hline
\end{tabular}

$\mathrm{Bu}$ çalışma kapsamında kullanılan panel veri setindeki serilerde YKB olması sebebiyle Tablo 4 yorumlanırken panel istatistiklerinin bootstrap olasılık değerleri dikkate alınmalıdır. Westerlund (2007) Eşbütünleşme Testi Sonuçları bulgularına göre, bütün yatay kesitler için eşbütünleşme ilişkisi yoktur şeklindeki boş hipotez $\% 5$ anlamlılık düzeyinde reddedilir. Buna göre, paneli oluşturan değişkenler arasında eşbütünleşik ilişki vardır. Bir başka deyişle bu seriler uzun dönemde birlikte hareket etmektedirler.

Panel veri analizinin sonraki aşamasında değişkenler arasındaki ilişkinin yönünün saptanması gerekmektedir. Modeldeki serilerin eğim parametrelerinin heterojen olması nedeniyle Dumitrescu ve Hurlin (2012) (D-H) panel nedensellik analizi tercih edilmiştir. D-H YKB'nin mevcut olduğu serilerde de güçlü sonuçlar verebilmektedir (Dumitrescu ve Hurlin 2012, 1450). D-H panel nedensellik testinde boş hipotez "bütün yatay kesitler için nedensellik yoktur" şeklindedir. Bu hipotezin test edilmesi için Wald istatistiği kullanılmaktadır. Wald istatistiği Denklem 15 ile formülize edilmektedir.

$$
W_{N, T}^{H n c}=\frac{1}{N} \sum_{i=1}^{N} W_{i, T}
$$


Veri setinde yatay kesit boyutu zaman boyutundan küçük olduğunda $(\mathrm{N}<\mathrm{T})$ asimptotik dağılıma sahip $Z_{N T}^{H N C}$ istatistiği, tersi durumda ise quasi asimptotik $Z_{N}^{H N C}$ istatistiği kullanılmalıdır:

$$
\begin{gathered}
Z_{N}^{H N C}=\frac{\sqrt{N}\left[W_{N, T}^{H n c}-N^{-1} \sum_{i=1}^{N} E\left(W_{i, T}\right)\right]}{\sqrt{N^{-1} \sum_{i=1}^{N} \operatorname{Var}\left(W_{i, T}\right)}} \\
Z_{N, T}^{H N C}=\sqrt{\frac{N}{2 K}\left(W_{N, T}^{H n c}-k\right)}
\end{gathered}
$$

D-H panel nedensellik testi bulguları Tablo 5'te sunulmuştur.

Tablo 5. Dumitrescu ve Hurlin (2012) Panel Nedensellik Testi Sonuçları

\begin{tabular}{|l|l|l|l|l|}
\hline Boş Hipotez & W İst. & Z-bar İst. & Olasılık Değeri & Karar \\
\hline DYY, EK'nın Nedeni Değildir & 1.55 & 0.96 & 0.33 & DYY $\nRightarrow$ EK \\
\hline EK, DYY'nin Nedeni Değildir & 2.22 & 2.12 & 0.03 & EK $\Rightarrow$ DYY \\
\hline
\end{tabular}

Tablo 5'te verilen D-H test bulguları, EK değişkeninden DYY değişkeni doğrultusunda tek yönlü nedensellik ilişkisinin mevcut olduğunu göstermektedir. Bir başka deyişle sermaye sahipleri BRICS-T ülkelerine, bu ülkelerdeki kompleks yapı ve üretim becerisi nedeniyle doğrudan yatırım getirmektedir.

Panel veri analizinde ilişkinin yönünden sonraki aşamada ilişkinin büyüklügünün test edilmesi gerekmektedir. Katsayı tahmininde kullanılacak olan tahmincinin belirlenmesinden önce serilerdeki otokorelasyon ve değişen varyansın test edilmesi gerekmektedir. Bu nedenle Wooldridge otokorelasyon testi ve değiştirilmiş Wald testi yöntemleri kullanılmıştır. Test bulguları Tablo 6'da özetlenmiştir.

Tablo 6. Wooldridge Otokorelasyon Testi ve Değiştirilmiş Wald Testi Bulguları

\begin{tabular}{|l|l|l|}
\hline Wooldridge Otokorelasyon Testi & Test İstatistiği & Olasılık Değeri \\
\hline Değiştirilmiş Wald Testi & 3.32 & 0.13 \\
\hline
\end{tabular}

Wooldridge otokorelasyon testinin boş hipotezi "birinci sıra otokorelasyon yoktur", değiştirilmiş Wald testinin boş hipotezi ise "değișen varyans sorunu yoktur" şeklindedir. Test bulgularına göre serilerde otokorelasyon sorunu mevcut olmamakla birlikte değişen varyans sorunu mevcuttur. Çalışmada kullanılan veri setinde değişen varyans sorunu ve YKB olması nedeniyle katsayı tahmininde bu sorunları dikkate alan Parks (1967) uygulanabilir genelleştirilmiş en küçük kareler (FGLS) tahmincisi kullanılmıştır. FGLS yöntemi ile tahminlenen panel veri modeli Denklem 18'de gösterilmektedir. 


$$
D Y Y_{i ; t}=\beta_{1}+\beta_{2} E K_{i, t}+\varepsilon_{i, t}
$$

D-H testi bulgularına dayanılarak; DYY modele bağımlı, EK ise bağımsız değişken olarak eklenmiştir. FGLS tahmin sonuçları Tablo 7'de yer almaktadır:

Tablo 7. FGLS Tahmin Sonuçları

\begin{tabular}{|l|l|l|l|l|}
\hline $\begin{array}{l}\text { Bağımlı } \\
\text { Değişken: DYY }\end{array}$ & Katsayı & Standart Hata & $\mathrm{Z}$ & $\mathrm{P}>\mathrm{zl}$ \\
\hline Sabit & 1.25 & 0.14 & 8.55 & 0.00 \\
\hline EK & 1.96 & 0.43 & 4.53 & 0.00 \\
\hline
\end{tabular}

FGLS modeli tahmin bulgularına göre Sabit katsayısı ve EK istatistiksel olarak \%1 düzeyinde anlamlıdır. EK ise DYY üzerinde pozitif etki meydana getirmektedir. Bulgular EK'da meydana gelecek olan 1 birimlik artışın DYY üzerinde 1,96 birimlik artışa yol açacağını göstermektedir. Tüm test bulguları genel olarak değerlendirildiğinde EK'nın DYY'nin Granger sebebi olduğu ve DYY üzerinde anlamlı pozitif etki meydana getirdiği saptanmıştır.

Elde edilen sonuçlar literatürdeki saptamalar ile karşılaştırıldı̆̆ında, analiz bulgularının nedensellik açısından Şahin ve Durmuş (2020) ile tutarlı olduğu görülmektedir. Çalışmada Meksika ve bu çalışmanın örnekleminde de yer alan Çin'de EK'dan DYY doğrultusunda tek yönlü nedensellik olduğu saptanmıştır. Katsayı tahmin modeli bulguları ise Gómez-Zaldívar vd. (2021) ile tutarlıdır. Çalışmada, Meksika ekonomisinde EK düzeyi yüksek olan bölgelerin daha yüksek oranda DYY aldığ́1 sonucuna ulaşılmıştır. Söz konusu çalışmaların yapıldığı ülkeler ile bu çalışma kapsamında ele alınmış olan ülkelerin benzer yapıda (bazılarının aynı) olması dikkat çekmektedir. Wang ve Wei (2008) ise Çin'de DYY'nin EK üzerinde istatistiksel olarak anlamlı bir etki meydana getirmediğini, sofistike ürün üretiminin çeşitli faktör donatılarından ve hükümet politikalarından etkilendiğini göstermişlerdir. Khan, Khan, ve Khan (2020) uzun dönemde değişkenler arasında çift yönlü, kısa dönemde ise EK'dan DYY doğrultusunda tek yönlü nedenselliğin olduğuna dair bulgular elde etmişlerdir. Sadeghi vd. (2020) günümüzde DYY akımlarının beşerî sermaye ve üretim kapasitesi becerisi arayışında olduğunu ampirik olarak kanıtlamıştır. Bu çalışmanın bulguları da bu doğrultudadır. Öte yandan Antonietti ve Franco (2021) yapmış oldukları nedensellik analizinde DYY'nin EK'nın Granger sebebi olduğuna dair kanıt elde etmişlerdir. Ancak bu etkinin çok küçük olduğunu ve sadece kişi başı milli gelirin, eğitimin ve finansal gelişmişliğin yüksek düzeyde olduğu ülkelerde görüldüğünü saptamışlardır. 


\section{Sonuç}

Dünyanın ekonomik yapısı sanayi temelli bir yaklaşımdan bilgi temelli bir çağa doğru dönüşümünü sürdürmektedir. Buna paralel olarak mikro ve makro bazdaki yöneticiler yönetim stratejilerini bu dönüşüm çerçevesinde güncellemektedirler. Çünkü geçmiş döneme ait kaideler geçerliliğini yitirmeye başlamıştır. Bu çalışmanın sonuçları da bu çerçevede şekillenmiştir. DYY hareketlerinin tarihsel gelişimi incelendiğinde sermayedarların geçmiş dönemlerde doğal kaynak arayışında olduğu görülmektedir. İzleyen dönemde ise pazar büyüklüğü DYY'nin coğrafi dağılımının belirleyicisi olarak önem kazanmıştır. DYY'nin hizmetlere ve yüksek teknolojili üretim alanlarına yöneldiği 1980'li yıllardan bu yana doğal kaynaklar, ucuz işgücü ve ulusal pazar büyüklüğü gibi geleneksel belirleyicilerin önemi azalmıştır. Günümüzde üretim becerileri, teknoloji, kurumlara ve ticaret anlaşmalarına erişim gibi faktörler kritik hale gelmiştir. Bu çalışmanın sonuçları bu iddiayı ampirik olarak desteklemektedir. Bulgular daha yüksek oranlı DYY girişi için EK'nın belirleyici ve pozitif etkili olduğunu göstermektedir. Bu bağlamda EK geliştirici eylemlerin yürürlüğe girmesi, sofistike ürün üretimini artırabilecek ve buna ilave olarak DYY girişlerini de hızlandıracaktır. Artan DYY çeşitli avantajları da beraberinde getirmektedir. Örneğin dünyanın en önemli ekonomileri arasında yer alan Çin'in başarısında DYY'nin önemli payı bulunmaktadır. BRICS-T ülkelerinin EK düzeylerini arttırmaları gelen DYY miktarını da arttıracaktır. Ayrıca BRICS-T ekonomilerinin belkemiği olan üretim ve hizmet sektörleri sofistike ürünlerle güçlendirilerek bu ülkelerin kırılganlıkları azaltılabilecektir. Özellikle kırılgan beşli grubunda yer alan Brezilya, Güney Afrika, Hindistan ve Türkiye'nin dışa bağımlı yapısı, makroekonomik ve finansal kırılganlıkları artırmaktadır. Güçlü bir üretim ile kur kaynaklı şokların etkisi minimize edilebilecektir. Bu amaçla beşerî sermayeyi geliştirecek eğitim/mesleki eğitim gibi faaliyetlerle birlikte kurumsal altyapının geliştirilmesi, yenilikçi faaliyetlerin desteklenmesi, fikri mülkiyet haklarının korunması ve yüksek teknolojili üretim yapan sektörlerin teşvik edilmesi gibi politikaların uygulanması gerekmektedir. 


\section{KAYNAKÇA}

Abubakirova, Aktolkin, Aziza Syzdykova, Assan Dosmakhanbet, Lyazzat Kudabayeva ve Gulnar Abdulina. 2021. "Relationship between Oil Prices and Stock Prices in BRICS-T Countries: Symmetric and Asymmetric Causality Analysis". International Journal of Energy Economics and Policy, 11(3): 140-148.

Acemoğlu, Daron. 2010. "Growth and Institutions". In Durlauf S.N., Blume L.E. (eds) Economic Growt, 107-15. Palgrave Macmillan, London.

Akiş, Elife, ve Semanur Soyyiğit. 2020. "Ekonomik Karmaşıklık Düzeyi ve CO2 Emisyonu Arasındaki İlişkinin Analizi: ASEAN Ülkeleri Örneği”. Yönetim Bilimleri Dergisi, 18 (38): 865-85.

Antonietti, Roberto, ve Chiara Franco. 2021. "From FDI to Economic Complexity: A Panel Granger Causality Analysis". Structural Change and Economic Dynamics, 56: 225-39.

Barro, Robert J., ve David B. Gordon. 1983. "Rules, Discretion and Reputation in a Model of Monetary Policy". Journal of Monetary Economics, 12 (1): 101-21.

Breusch, Trevor S., ve Adrian R. Pagan. 1980. "The Lagrange Multiplier Test and Its Applications to Model Specification in Econometrics". The Review of Economic Studies, 47 (1): 239-53.

Can, Muhlis, ve Buhari Doğan. 2018. "Ekonomik Kompleksite ve Finansal Gelişme İlişkisi: Türkiye Örnekleminde Ampirik Bir Analiz”. Finans Politik \& Ekonomik Yorumlar, 55 (638): 5-16.

Chávez, Juan Carlos, Marco T. Mosqueda, ve Manuel Gómez-Zaldívar. 2017. "Economic Complexity and Regional Growth Performance: Evidence from the Mexican Economy”. Review of Regional Studies, 47 (2): 201-19.

Dumitrescu, Elena-Ivona, ve Christophe Hurlin. 2012. "Testing for Granger Non-Causality in Heterogeneous Panels". Economic Modelling, 29 (4): 1450-60.

Durlauf, Steven N. 1998. "What Should Policymakers Know About Economic Complexity?" Washington Quarterly, 21 (1): 155-65.

Eren, Ercan. 2013. “Kompleksite İktisadı ve Ajan-Temelli Modelleme: Metodolojik Bir Yaklaşım”. Discussion Paper No. 2013/3. Turkish Economic Association, Ankara.

Fontana, Magda. 2010. "Can Neoclassical Economics Handle Complexity? The Fallacy of the Oil Spot Dynamic". Journal of Economic Behavior \& Organization, 76 (3): 584-96.

Gómez-Zaldívar, Manuel, Irving Llamosas-Rosas, ve Fernando Gómez-Zaldívar. 2021. "The Relationship between Economic Complexity and the Pattern of Foreign Direct Investment Flows among Mexican States". Review of Regional Studies, 51 (1): 64-88.

Güneri, Barbaros. 2019. "Economic Complexity and Economic Performance". Ph.D. Dissertation, Hacettepe University Graduate School of Social Sciences.

Gylfason, Thorvaldur. 2001. "Natural Resources, Education, and Economic Development". European Economic Review, 45 (4-6): 847-59.

Hartmann, Dominik, Miguel R. Guevara, Cristian Jara-Figueroa, Manuel Aristarán, ve César A. Hidalgo. 2017. "Linking Economic Complexity, Institutions and Income inequality". World Development, 93: 75-93.

Hausmann, Ricardo, ve César A. Hidalgo. 2011. "The Network Structure of Economic Output". Journal of Economic Growth, 16 (4): 309-42.

Hidalgo, César A. 2009. "The Dynamics of Economic Complexity and the Product Space Over a 42 Year Period". CID Working Paper No. 189. Center for International Development Working Papers: Harvard University.

Hidalgo, César A., ve Ricardo Hausmann. 2009. "The Building Blocks of Economic Complexity”. Proceedings of the National Academy of Sciences, 106 (26): 10570-75.

Javorcik, Beata S., Alessia Lo Turco, ve Daniela Maggioni. 2018. "New and İmproved: Does FDI Boost Production Complexity in Host Countries?" The Economic Journal, 128 (614): 2507-37.

Karakurt, Izzet. 2021. "Modelling and Forecasting the Oil Consumptions of the BRICS-T Countries". Energy, 220, 119720. https://doi.org/10.1016/j.energy.2020.119720

Khan, Hameed, Umair Khan, ve Muhammad Asif Khan. 2020. "Causal Nexus Between Economic Complexity and FDI: Empirical Evidence From Time Series Analysis”. The Chinese Economy, 53 (5): 374-94.

Li, Xiaoying, ve Xiaming Liu. 2005. "Foreign Direct İnvestment And Economic Growth: An İncreasingly Endogenous Relationship". World Development, 33 (3): 393-407.

Mattoo, Aaditya, Marcelo Olarreaga, ve Kamal Saggi. 2004. "Mode of Foreign Entry, Technology Transfer, and FDI Policy". Journal Of Development Economics, 75 (1): 95-111.

Parks, Richard W. 1967. "Efficient Estimation of a System of Regression Equations When Disturbances are Both Serially and Contemporaneously Correlated". Journal of the American Statistical Association, 62 (318): 500-509.

Pesaran, M. Hashem. 2007. “A Simple Panel Unit Root Test in the Presence of Cross-Section Dependence”. Journal of Applied Econometrics, 22 (2): 265-312.

Pesaran, M. Hashem, ve Takashi Yamagata. 2008. "Testing Slope Homogeneity in Large Panels". Journal of Econometrics, 142 (1): 50-93. 
Pinheiro, Flávio L., Aamena Alshamsi, Dominik Hartmann, Ron Boschma, ve César Hidalgo. 2018. "Shooting Low or High: Do Countries Benefit from Entering Unrelated Activities?" Papers in Evolutionary Economic Geography, 18 (07).

Romer, Paul M. 1990. “Endogenous Technological Change”. Journal of Political Economy, 98 (5, Part 2): S71102.

Sadeghi, Pegah, Hamid Shahrestani, Kambiz Hojabr Kiani, ve Taghi Torabi. 2020. "Economic Complexity, Human Capital, and FDI Attraction: A Cross Country Analysis”. International Economics, 164: 168-82.

Simoes, Alexander James Gaspar, ve César A. Hidalgo. 2011. "The Economic Complexity Observatory: An Analytical Tool For Understanding the Dynamics of Economic Development". In Workshops at the twenty-fifth AAAI conference on artificial intelligence.

Soyyiğit, Semanur, Hüseyin Topuz, ve Halil Özekicioğlu. 2019. "Ekonomik Kompleksite, İhracat ve Sabit Sermaye Yatırımlarının Kişi Başına Düşen Gelir Üzerindeki Etkisi: G-20 Ülkeleri Örneği”. Mehmet Akif Ersoy Üniversitesi İktisadi ve İdari Bilimler Fakültesi Dergisi, 6 (2): 393-407.

Swamy, Paravastu A. V. B. 1970. "Efficient Inference in a Aandom Coefficient Regression Model". Econometrica: Journal of the Econometric Society, 311-23.

Swart, Julia, ve Lisa Brinkmann. 2020. "Economic Complexity and the Environment: Evidence from Brazil". In Universities and Sustainable Communities: Meeting the Goals of the Agenda 2030, 3-45. Springer.

Şahin, Dilek, ve Savaş Durmuş. 2020. "Yeni Sanayileşen Ülkelerde Ekonomik Kompleksite Düzeyinin Belirleyicileri”. ODÜ Sosyal Bilimler Araştırmaları Dergisi, 10 (2): 334-51.

Torun, Mustafa, ve Meral Çabaş. 2019. "Doğrudan Yabancı Sermaye Yatırımlarının Sofistike Ürün Üretimi Üzerindeki Etkisi: Türkiye Örneği”’. 5. Uluslararası Ekonomi Yönetimi ve Pazar Araştırmaları Kongresi, İstanbul, 27 Eylül 2019, 75-84.

Ünzüle, Kurt. 2018. "Küreselleşme ve Ekonomik Kompleksite İlişkisi: Türkiye Örneği”. Hitit Üniversitesi Sosyal Bilimler Enstitüsü Dergisi, 11 (3): 2195-2202.

Wang, Zhi, ve Shang Jin Wei. 2008. "What Accounts for the Rising Sophistication of China's Exports". NBER Working Paper. No. 13771. Massachusetts, Cambridge: National Bureau of Economic Research.

Westerlund, Joakim. 2007. "Testing for Error Correction in Panel Data". Oxford Bulletin of Economics and statistics, 69 (6): 709-48.

Yalta, A. Yasemin, ve Talha Yalta. 2021. "Determinants of Economic Complexity in MENA Countries". Journal of Emerging Economies and Policy, 6 (1): 5-16.

Yıldırım, Durmuş Çağrı, Seda Yıldırım ve Işsıl Demirtas. 2019. "Investigating Energy Consumption and Economic Growth for BRICS-T countries". World Journal of Science, Technology and Sustainable Development, 16(4): 184-195.

Zhu, Lei, ve Bang Nam Jeon. 2007. "International R\&D spillovers: Trade, FDI, and information technology as spillover channels". Review of International Economics, 15 (5): 955-76.

Zhu, Shujin, ve Renyu Li. 2017. "Economic Complexity, Human Capital and Economic Growth: Empirical Research Based on cross-Country Panel Data". Applied Economics, 49, (38): 3815-3828. 